\title{
Business modeling process for university's technology transfer offices
}

\author{
Alexandru MARIN \\ University POLITEHNICA of Bucharest, Bucharest, Romania \\ alexandru.marin@upb.ro \\ Alexandra HADĂR \\ University POLITEHNICA of Bucharest, Bucharest, Romania \\ Anca Alexandra PURCĂREA \\ University POLITEHNICA of Bucharest, Bucharest, Romania \\ Laura BOANȚĂ \\ University POLITEHNICA of Bucharest, Bucharest, Romania
}

\begin{abstract}
The present paper is devoted to analyze the appropriate recommendations to increase the effectiveness of technology transfer centers from Romanian National Network for Innovation and Technology Transfer - ReNITT, hosted by universities. The study is focused on the definition of a conceptual frame to develop specific business models, by the specialized compartments from technology/ knowledge transfer entities, and using the specific instruments of business modeling process. The qualitative and quantitative analysis of the 8 steps scheduling of pairing the building blocks of the Business Models Canvas, corresponding to the specific technology transfer models, and taking into account the elements of the value chain of technology transfer and making connections with technology readiness level, allows a clarification of this relative "fuzzy" and complicated modeling process of university's Technology Transfer Offices activities, gathering in a concentrated format all necessary information. According to their mission, objectives and strategies, universities decide upon a certain business model for the Technology Transfer Offices, adaptable to client segment and value proposition to attain, by the offered services portfolio. In conclusion, during their activities, Technology Transfer Offices identify, validate and exploit the opportunities originated from applicative research results, by "technology push" methods. Also, there are necessary specific competences (human and material) to develop externally aware business models starting from real needs of the clients, by "market pull" techniques, that would contribute to enhance the endogenous innovation potential of firms.
\end{abstract}

Keywords: technology transfer office, business model canvas, technology transfer models, technology transfer value chain, technology readiness level.

\section{Introduction}

The rapid commercialization of the research results, coming from institutes, universities or companies, is the key of local, regional or national competitiveness in actual knowledge based and innovation driven economy.

Today, more than $60 \%$ of the multi-national companies develop technologies through "open innovation" mechanism, strongly cooperating with independent research entities, public or private. Also, over $89 \%$ of the successful technology 
transfer activities contribute to the competitiveness of the innovative SME's from economic developed countries.

At European level, starting from 1996 with Innovation Relay Center, followed by EEN (Enterprise Europe Network), is active the largest global network for supporting research and innovation. In Romania, we have ReNITT - a national network for innovation and technology transfer, but the results are not satisfactory concerning its positive impact on our national socio-economic environment.

In a common approach concerning their business model, technology transfer organizations provide services for the development of knowledge transfer, as support of the competitiveness of public and private clients, and for the benefit of society.

The present paper is devoted to analyze the appropriate recommendations to increase the effectiveness of technology transfer centers from Romanian National Network for Innovation and Technology Transfer - ReNITT, hosted by universities. The study is focused on the definition of a conceptual frame to develop specific business models, by the specialized compartments from technology/ knowledge transfer entities, and using the specific instruments of Business Model Canvas, associated to the technological transfer value chain for value added services addressed to their clients. All these objectives were followed in the frame of the modern "third mission" of universities, by encapsulating the rising demands to take a more visible role in stimulating and guiding the utilization of knowledge for social, cultural and economic development.

\section{Literature review}

Knowledge transfer approach is more adequate than "traditional" technology transfer, in the context when innovation contributes essentially to growth, competitiveness and employment in the actual knowledge based economy. Also, innovation is more "open", and scientific research activities contributes essentially to successful knowledge transfer. In EU countries and globally, the most important technology transfer activities are: IPR protection; technology commercialization; new innovative ventures support; adequate management of applicative research contracts. Independent technology transfer organizations are focused on spin-off support / assistance, i.e. business incubators or accelerators. This specificity relies on concerted action of public authorities, chambers of commerce or industry associations, with a strong emphasis on regional economic development. In recent years, there has been greater interest in creating spin-off companies, mainly when the newly created technology has a relative broad area of practicability, although it is a complex and expensive process, the rate of "mortality" in the early years being high, only very few succeeding to become large firms of surviving in the market (Marin et al., 2015).

Innovation is more and more dependent on external sources of knowledge for the development and improvement of product / process innovations. Various types of actors who act as knowledge / technology transfer intermediaries are considered by many as "essential components" connecting the suppliers to the beneficiaries of knowledge. Publicly funded technology transfer offices, hosted in universities and public research organizations, publicly funded regional economic development agencies, knowledge-intensive business service firms, professional associations, advisory bodies and knowledge workers could all be considered as intermediaries 
that facilitate the transfer of knowledge supporting the innovation process in firms. Each type of intermediary has a different status and achieves a different role in the innovation process of firms (Landry et al., 2013).

No doubt, universities are the most important knowledge source also supporting technological innovation. Innovation, in its technology component, is a dynamic process, much more based upon a complex and multidisciplinary knowledgebased approach. In this context, universities were encouraged to put more effort into developing interdisciplinary curricula and creating industry linkages in order to shorten time to prototyping and identifying market needs. In this context, universities are today "hybrid organizations" where science and business and "playing together", even they prescribe different behaviors, such as open publication and the pursuit of knowledge development, more than commercial exploitation of research outcomes, driven only to profit (Baglieri et al., 2015).

\section{Problem formulation}

Knowledge and technology transfer from universities usually implies licensing technologies and creation of spin-off companies. New companies are mostly academic spin-offs, while independent entrepreneurs are involved by having a licensing agreement with the university. Technology licensing and start-ups play specific roles, oriented only to particular areas of the university technology transfer, promoting the development of an innovative ecosystems, and exploiting in an efficient manner the entrepreneurial opportunities.

Specifically, academic staff and researchers are the key actors which are active in different organizational structures (e.g. departments and research centers), while established firms and spin-off companies play a crucial role in commercial exploitation of the research results. Also, universities are selective when working with large or small firms, in the way they promote internal scientific disclosure by faculty members, and, their willingness to use non-exclusive licensing agreements vs. exclusive ones. These aspects confirm the existence of different business models that universities may use in their technology transfer activities. Because knowledge / technology transfer involves different key actors in knowledge-based exploration (i.e. researchers) and value exploitation (e.g. existing firms, new ventures, and potential entrepreneurs), universities are looking very careful to find the right balance between internal and external stakeholders. This distinction between global and local stakeholders determines specific practices that universities use to provide incentives as motivation instruments for academic staff and researchers. These mechanisms could be addressed in equal mode to all departments or to be focused only on exceptional researchers that are acquainted with managerial issues related to industry collaboration, case not very often observed. Organizational practices targeting these two approaches configure different revenue generation patterns and consequently affect future technology transfer activities. In this respect, the dynamic interplay between aspects analyzed before could be integrated into a framework of university technology transfer that consists of four different quadrants that result from different configurations of key elements representing business models (Baglieri

et al., 2015). In Figure 1 are presented the various modes and corresponding 
challenges related to strategic thinking that universities must deal with, in each of these specific models.

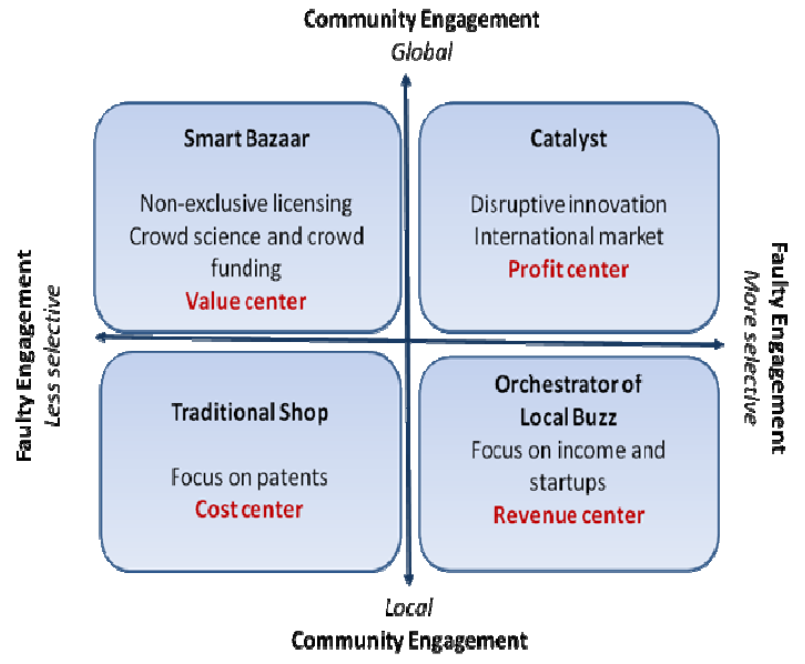

PICBE | 1036

Figure 1. A framework of university TTO business models

Source: http://druid8.sit.aau.dk/acc_papers/159889emvut56oldvoc5eps4a9jp.pdf.

\section{Model „cost center” - Technology transfer as “Traditional shop"}

In this model, technology transfer to the market of the research results is configured by using the classical mechanisms, the activities destined to increase of intellectual property culture and protecting intellectual property rights being uniformly distributed, with no selection or prioritizing mechanism, to all departments of a university. The strategic orientation is focused to increase scientific visibility in international data bases and in tight connection to the "academic performance". The efficiency and degree of performance is evaluated, i.e. by number of valid patents owned by university, IP management process of assessing their valorization potential being done at the basis level of organization structures (departments, research centers etc.).

The main activities that Technology Transfer Offices (TTOs) carry on are: promotion of patenting and tactical mechanisms of preserving the right to get IPR protection (e.g., postponing publication until after patent application, sanitizing data for publication, etc.). Usually, university is the owner of the patent, as result of sponsored inventions, including those inventions that have benefited of using the university's human and material facilities, in accordance to their patent policy. Regarding technology transfer revenues, universities manifest little or limited interest in licensing technologies for some money income, this approach expressing that technology transfer is seen as a "cost center" and not as a "revenue center".

For organizations dealing with knowledge / technology transfer acting regionally is important to be valorized the geographical proximity of potential clients (innovative SMEs and spin-off / start-up companies), especially in the new context of RIS - regional innovation strategies from our country and in the frame of open innovation approach, with an increased degree of outsourcing the research and development activities. 


\section{Model "revenue center" - Technology transfer as "Orchestrator of Local Buzz”}

In this model, the technology transfer is specific to universities that act entrepreneurially, in order to accomplish their "third mission", supplementary to their classical mission for education and research in the benefit of knowledge development.

The entrepreneurial orientation emphasize the importance of capitalization the new scientific and technological opportunities, following to boost local, regional, national and global economic development. This new tendency encourages universities to broaden the range of university-industry relationships, favoring also social interactions with local actors, acting in all fields of activity. Today, most universities recognize that traditional technology transfer approaches aren't anymore adequate to serve their objectives, and need to go beyond patenting and licensing agreements or being satisfied just with more equitable contracts of sponsored research, so they tend to fully participate as partners in more entrepreneurial programs and becoming active stakeholders in different social and economic contexts.

New forms of knowledge transfer are associated with the dichotomy between tacit and explicit knowledge. Because tacit knowledge is difficult to be quantified and is hard to be formalized and communicated its transfer requires close social interaction between people and is difficult to be managed. On the other side, explicit knowledge is more easily to be formalized and universities have developed various sorts of IP policies to protect this form of knowledge and capture its value. Although most of the knowledge at a university is explicit, the development of emerging technologies requires the active involvement of inventors, beyond licensing agreements. In some rare cases, academic researchers decide to pursue the development of their inventions by spinning out a new company. The interaction between university and its social and economic environment is mediated by technology transfer organizations, their managers devoting a special attention to start-up companies and their role in the local ecosystem. In this respect, universities are often willing to manage physical spaces (i.e. incubators, innovation labs, accelerators) to promote the on entrepreneurial culture and initiative.

Also, there are some complementary methods of collaboration between universities and local communities, as follows:

Non-academic professional training, viewed as long life learning activities, for improving knowledge, skills and competences of natural persons, from civic, social, employment perspective;

- $\quad$ Social responsibility, defined as partnership between academic community and stakeholders from public and private domain, destined to improve tuition level, research and creativity aptitudes, citizenship education, strengthening democratic values, civic responsibility and contribution to the welfare of society.

In this respect, the knowledge / technology transfer activities represent revenue sources, relevant for overcoming financial constraints and supporting research development. Is important to impose a minimum threshold of profitability, used to offer some bonuses to inventors and to ensure certain supplementary funding for educational and research processes in universities. 


\section{Model "profit center" - Technology transfer as “Catalyst”}

Recently, more and more of universities emerged as "global players" in the universityindustry collaboration, in order to develop radical / disruptive innovations, some of them being able to solve societal issues. According to this tendency, many successful technology transfer offices "pushed" and were interested mainly for the highest revenues, in fact being profitable, which is very seldom the normal case. Consequently, universities with strong patent policies have also adequate royalty sharing policies to provide incentives to researchers, encouraging them to actively participate in the technology transfer process. These universities are also more interested to grant exclusive licenses, for large amount of money, since exclusivity is reasonably needed to encourage firms' to invest and develop highly competitive technologies. Some university technologies that were the most successful in industry collaborations didn't exist before, thus the markets were not easily identifiable or quantifiable at an early stage.

Thus, universities that are "catalysts" are able to engage both small and large companies, and promote entrepreneurship as well, especially to develop early stage inventions. In this manner, they align commercial logic with the academic setting, where the core mission of the institution is education, research, and community services. Also, it is necessary to have a rigorous control of associated risks and a good capacity of anticipation for rapid technology evolution, especially in domains with high-speed changing rate, like information and communication technologies.

\section{Model "value center" - Technology transfer as "Smart bazaar"}

This model is adequate to universities that are interested to develop knowledge, both in the benefit of students and whole society, since they assume their responsibility to respond to human needs, with particular emphasis on those of underserved populations, and engage people in knowledge production and dissemination. In this context, universities are more aware that the target to generate revenues should not prevail, against the importance of moving innovation to society, where intended impact could be achieved. Accordingly, universities engage more deeply faculty participation in disclosure of inventions and encourage licensing agreements to be more flexible in terms of deals structure, by preferring non-exclusive terms instead of exclusive ones.

So, universities are trying to become less interested to seek only financial interests and revenue generation and strategically orient to a more open-sourced model of technology transfer. In this view, technology transfer office is seen as a "smart bazaar" which makes university discoveries accessible to society and encourages value creation against money revenue generation. Complementary, big data and crowdfunding mechanisms lead to an alternative technology transfer business model based on the principles that societal engagement and openness would alleviate the need to measure revenue-based performance. Thus, nowadays most powerful universities launched their online crowdfunding platform, for providing critical fundraising support for innovative projects by faculty and student 
organizations. Also, open data promotes a wider involvement of the international scientific community and enhance the importance of creativity and societal problem solving.

The detailed analyze presented above emphasizes once more that universities takes a variety of methods to configure their technology transfer processes, reflected clearly in their existing business models and inspiring the desired business model innovation. New relationships and connections within the local ecosystem are needed, the business model innovation becoming almost an exclusive knowledge developing activity, creating new ways and methods for organizing the university technology transfer. The use of business model as a "cognitive instrument" attracts the fact that new roles of technology transfer can be defined. For example, universities that intend to transform their technology transfer business model from "cost center" to "profit center" must become more selectively both in patenting and licensing agreements. This is consistent with the practical conclusion that the productivity of knowledge transfer decreases once universities attain a certain rate of academic patenting.

In a vertical direction, is identified one very new tendency - from local to global approach - challenging TTOs to enhance their visibility in the international markets. Finally, when getting from closed to open approach, the fact is connected to the actual challenges of digital economy and the potential of big data implications in co-creation and co-innovation.

As stated in the introduction, we wish to define a conceptual frame to develop specific business models, by the specialized compartments from technology / knowledge transfer entities, and using the specific instruments of Business Model Canvas, associated to the technological transfer value chain for value added services addressed to their clients. This value chain contains three essential value propositions:

- Exploration of knowledge-based opportunities;

- Technical validation of knowledge-based opportunities;

- Exploitation of knowledge-based opportunities (legal issues, access to capital, commercialization).

\section{Results and discussion}

The instruments for building the Business Model Canvas comprise the needed "key drivers" of a business ( 9 building blocks): customer segments, value proposition, customer relationships, channels of cooperation, revenue streams, key activities, key resources, key partners and cost structure. The algorithm of pairing building blocks structures the information and schedule the successive steps, to be presented as follows. With these elements, containing certain quantitative and qualitative details, it's possible to make a comparative analysis of the corresponding business models associated to the four technology transfer models presented above.

In the following description, we will give detailed explanation of characteristics only for the technology transfer model: "revenue center" type ("Orchestrator of Local Buzz"); for the other technology transfer models, explanations are similar, the limited space allocated to this paper making impossible their specific presentation, given in the contract 10S/04.02.2015, financed by Sectoral Research Program of National 
Authority for Research, Development and Innovation (http://www.upb.ro/acasa.html).

\section{Step 1 - pairing customer segments with value propositions}

Technology readiness level - TRL envisages as result of the offered services for knowledge / technology transfer depends on the position in the value chain and on the category of clients, as presented in Figure 2. Value proposition are assimilated with the three elements of the technology transfer value chain and we have segmented three customer segments, following reasonable criteria relying to their position in the market (type of activities and dimension of organization). If the clients are SMEs, the value proposition is personalized, with clear market strategies, for generating substantial revenues. In the case of large companies, or other types of similar organizations, the value proposition is flexible and not-differentiated, or only partial personalized.

Services range is relative widespread, covering from consultancy (30-40\%), support for integrating in research projects or direct collaborations (30-40\%), access to high performance infrastructure in host institution or in partnership with other organizations, including professional training services (20-40\%).

\begin{tabular}{|l|l|l|l|l|}
\hline CS - VP & VP1 & VP2 & VP3 & \\
\hline CS1 (50\%) & TRL 1-3 & & \\
\hline CS2 (10\%) & TRL 2-3 & TRL 4-5 & TRL 6-7 & \\
\hline CS3 (40\%) & & & TRL 2-7 & \\
\hline CS1 (30\%) & TRL 1-3 & & & \\
\hline CS2 (20\%) & TRL 2-3 & TRL 4-5 & TRL 6-7 & \\
\hline CS3 (50\%) & & & TRL 2-7 & \\
\hline CS1 (40\%) & TRL1-3 & & & \\
\hline CS2 (15\%) & TRL 2-3 & TRL 4-5 & TRL 6-7 & \\
\hline CS3 (45\%) & & & TRL 2-7 & \\
\hline CS1 (60\%) & TRL 1-3 & & & \\
\hline CS2 (10\%) & TRL 2-3 & TRL 4-5 & TRL 6-7 & \\
\hline CS3 (30\%) & & & TRL 2-7 \\
\hline
\end{tabular}

Figure 2. Pairing customer segments with value propositions

Source: Authors' own research. 


\section{Step 2 - pairing customer segments with channels of cooperation}

The channels of interaction / cooperation with clients depend on their category, as presented in Figure 3, the proportions being associated with preferences and availability of clients, corresponding to their day-to-day activities and available financial, logistic and time resources.

\begin{tabular}{|l|c|c|c|}
\hline CS - C & C1 & \multicolumn{1}{l|}{ C2 } & C3 \\
\hline CS1 & $20 \%$ & $60 \%$ & $20 \%$ \\
\hline CS2 & $60 \%$ & $35 \%$ & $5 \%$ \\
\hline CS3 & & $60 \%$ & $40 \%$ \\
\hline CS1 & $40 \%$ & $40 \%$ & $20 \%$ \\
\hline CS2 & $70 \%$ & $25 \%$ & $5 \%$ \\
\hline CS3 & $10 \%$ & $50 \%$ & $40 \%$ \\
\hline CS1 & $30 \%$ & $50 \%$ & $20 \%$ \\
\hline CS2 & $70 \%$ & $25 \%$ & $5 \%$ \\
\hline CS3 & $20 \%$ & $50 \%$ & $30 \%$ \\
\hline CS1 & $40 \%$ & $40 \%$ & $20 \%$ \\
\hline CS2 & $60 \%$ & $35 \%$ & $5 \%$ \\
\hline CS3 & $15 \%$ & $50 \%$ & $35 \%$ \\
\hline
\end{tabular}

PICBE | 1041

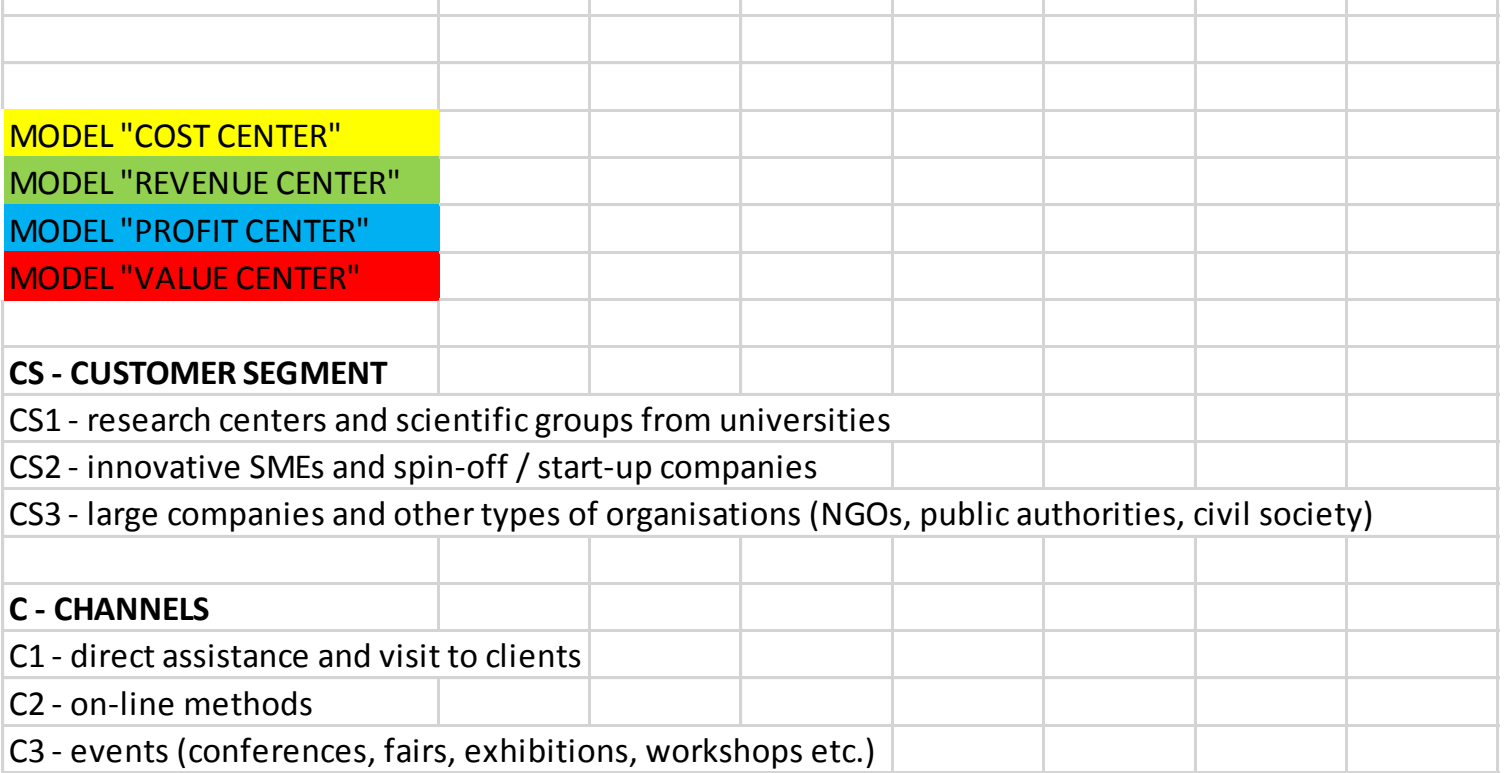

Figure 3. Pairing customer segments with channels of cooperation

Source: Authors' own research.

\section{Step 3 - pairing customer segments with customer relationships}

In connection with the channels of cooperation, the content of services offered to clients is segmented in four major categories, their weight distribution being presented in Figure 4. Assistance and personalized services are dominant for clients CS2 and CS3, while general consultancy is more present for clients CS1. Necessity of long life learning education is requested mainly by categories CS3 and CS1, and services for information / documentation are needed mostly to clients CS1 and CS2. 


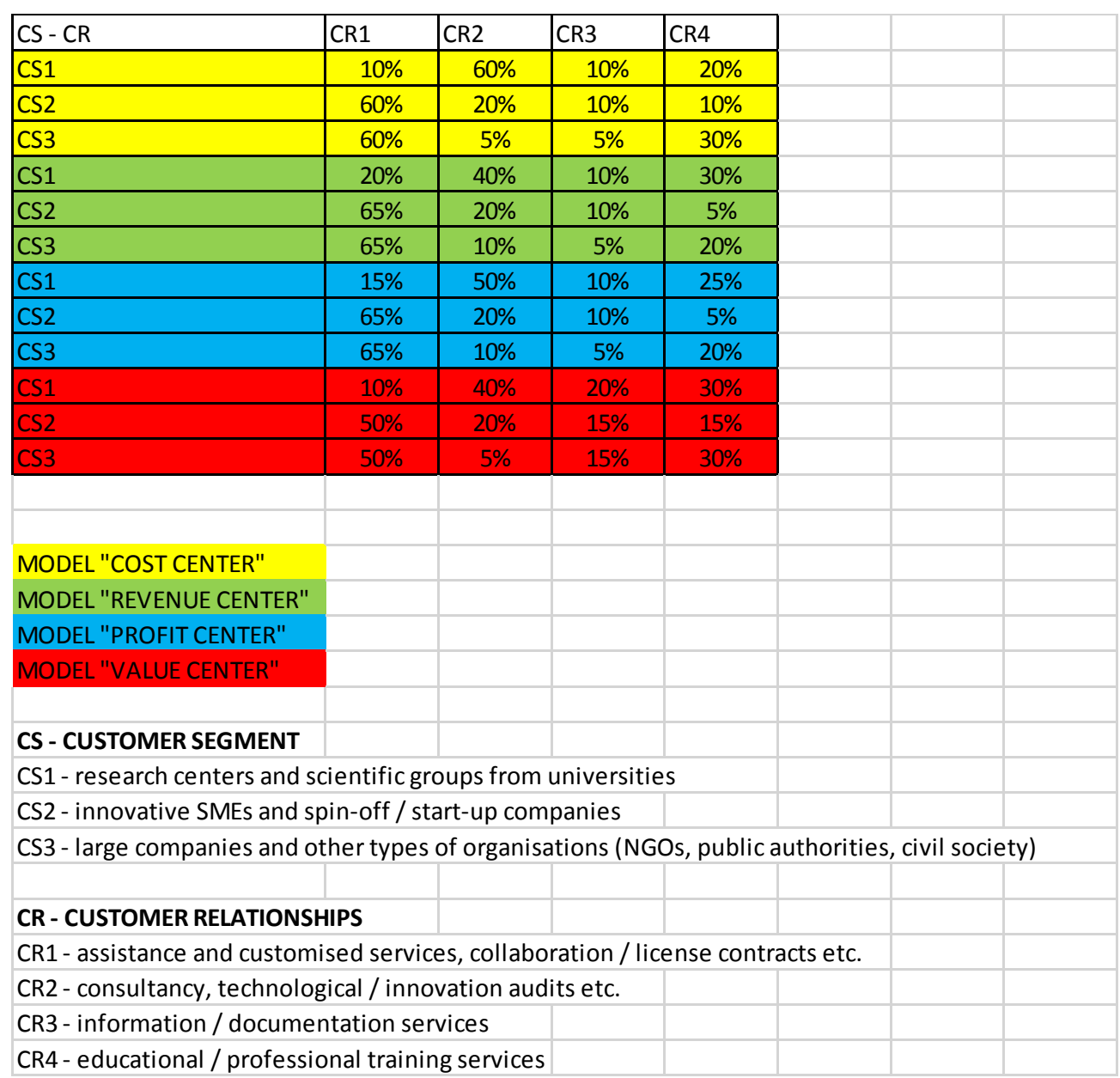

PICBE | 1042

Figure 4. Pairing customer segments with customer relationships

Source: Authors' own research.

\section{Step 4 - pairing customer segments with revenue streams}

Revenues (financial resources) of TTO are coming from external sources (grants from European, national and regional programs) or from host institution - up to $70 \%$ from total expenses, $30 \%$ being covered by clients paying for their received services. This structure of revenues allows offering competitive prices for the services, especially for the clients coming from academic environment and for SMEs. The distribution of the revenue sources is presented in Figure 5 and depends on the category of clients, and on the type of available financing source. Is important to mention the existence of a core funding, "nucleus" type from public programs, as important support for sustainability of current activities, which add the support of host organization (cofinancing part of the projects financed from public sources), partially covering some salaries expenses etc. Income from participation fees to organized events and share of the royalties coming from licensing technologies, along with sponsorships, donations etc. are completing the possible revenue sources for TTOs activities. 


\begin{tabular}{|c|c|c|c|c|c|c|c|}
\hline $\mathrm{CS}-\mathrm{RS}$ & RS1 & RS2 & RS3 & RS4 & RS5 & RS6 & RS7 \\
\hline CS1 & & & & & $5 \%$ & & $10 \%$ \\
\hline CS2 & $10 \%$ & $5 \%$ & & & $5 \%$ & & $10 \%$ \\
\hline CS3 & $15 \%$ & $10 \%$ & $5 \%$ & $8 \%$ & $5 \%$ & $2 \%$ & $10 \%$ \\
\hline CS1 & & & & & $3 \%$ & & $10 \%$ \\
\hline CS2 & $5 \%$ & $5 \%$ & & & $3 \%$ & & $10 \%$ \\
\hline CS3 & $15 \%$ & $10 \%$ & $10 \%$ & $13 \%$ & $4 \%$ & $2 \%$ & $10 \%$ \\
\hline CS1 & & & & & $3 \%$ & & $10 \%$ \\
\hline $\mathrm{CS} 2$ & $5 \%$ & $5 \%$ & & & $3 \%$ & & $10 \%$ \\
\hline CS3 & $15 \%$ & $10 \%$ & $10 \%$ & $13 \%$ & $4 \%$ & $2 \%$ & $10 \%$ \\
\hline CS1 & & & & & $6 \%$ & & $10 \%$ \\
\hline CS2 & $5 \%$ & $5 \%$ & & & $6 \%$ & & $10 \%$ \\
\hline CS3 & $10 \%$ & $10 \%$ & $5 \%$ & $13 \%$ & $8 \%$ & $2 \%$ & $10 \%$ \\
\hline \multicolumn{8}{|c|}{ MODEL "COST CENTER" } \\
\hline \multicolumn{8}{|c|}{ MODEL "REVENUE CENTER" } \\
\hline \multicolumn{8}{|c|}{ MODEL "PROFIT CENTER" } \\
\hline \multicolumn{8}{|c|}{ MODEL "VALUE CENTER" } \\
\hline \multicolumn{8}{|c|}{ CS - CUSTOMER SEGMENT } \\
\hline \multicolumn{8}{|c|}{ CS1 - research centers and scientific groups from universities } \\
\hline \multicolumn{8}{|c|}{ CS2 - innovative SMEs and spin-off / start-up companies } \\
\hline \multicolumn{8}{|c|}{ CS3 - large companies and other types of organisations (NGOs, public authorities, civil society) } \\
\hline \multicolumn{8}{|c|}{ RS - REVENUE STREAMS } \\
\hline \multicolumn{8}{|c|}{ RS1 - project financing (POC, POCU, POR, PNCDI, H2O20 etc.) } \\
\hline \multicolumn{8}{|c|}{ RS2 - service payments from clients } \\
\hline \multicolumn{8}{|c|}{ RS3 - royalties / revenues from licensing / selling technologies } \\
\hline \multicolumn{8}{|c|}{ RS4 - partcipation fees at organised events } \\
\hline \multicolumn{8}{|c|}{ RS5 - host institution financial support (projects co-financing, partial support of expenses etc.) } \\
\hline \multicolumn{8}{|c|}{ RS6 - sponsorships, donations etc. } \\
\hline RS7 - co & "type, $\mathrm{fr}$ & m public & burces & & & & \\
\hline
\end{tabular}

PICBE | 1043

Figure 5. Pairing customer segments with revenue streams

Source: Authors' own research.

\section{Step 5 - pairing value propositions with "key" activities}

The correlations between the services from the value chain of knowledge / technology transfer, offered by TTOs, and the corresponding necessary activities are presented in Figure 6. The hierarchy of activities weights is: A4, A6, A2, A1, A3, in descending order. Explanation is simple: in exploration and exploitation / valorization of knowledge based opportunities, essential is the assistance for invention disclosures, filing and granting patents and other IPR instruments and their valorization (A4), corroborated with support activities for managing the portfolio of intangible assets (A6). Support activities for licensing IPR / intangible assets and knowledge capital (A2), support activities for selling innovative products / technologies / services and technology brokerage (A1) and assistance for negotiating Research Development Innovation and Tech Transfer contracts (A3) are completing the list of "key activities" necessary for an efficient knowledge / technology transfer. 


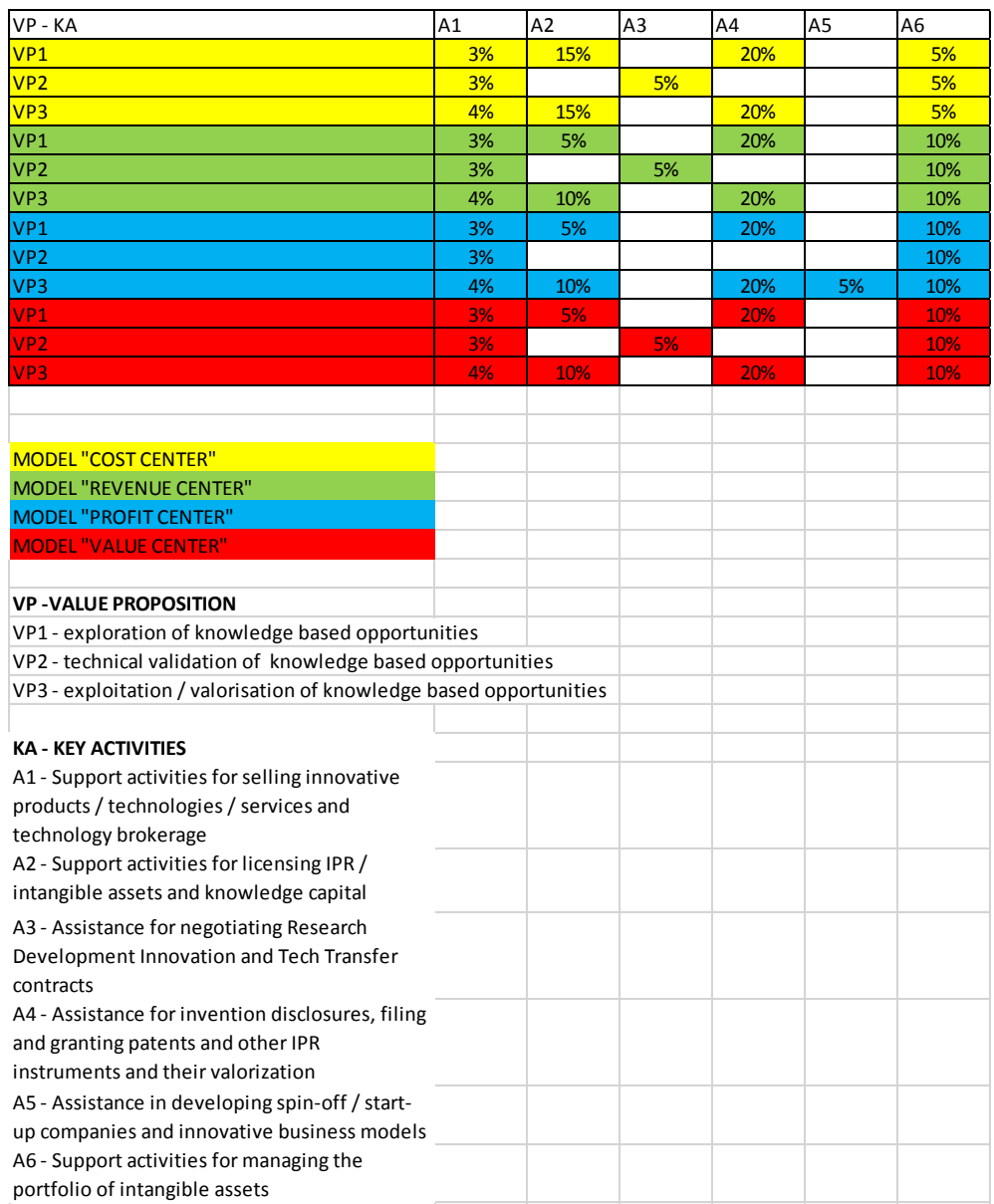

Figure 6. Pairing value propositions with "key" activities

Source: Authors' own research.

\section{Step 6 - pairing "key" activities with "key" resources}

"Key" resources allocated for the necessary activities of TTO are presented in Figure 7. There are activities with unique resource allocation (i.e. A4 with KR1): assistance for developing experimental models and prototypes needs only technical facilities (own and/or in cooperation / partnership). Similar is the situation with A7 KR4: professional training and logistic support in knowledge / technology transfer authorized programs for education / professional training and A8 - KR2: organizing thematic events and support for dissemination, promotion, marketing in technology commercialization - multi-media facilities in host institution and logistics for events.

On the other hand, there are 6 activities that needs 1 "key" resource allocation / professional expertise, i.e. A1, A2, A3, A5, A6, A9 with KR3: support activities for selling innovative products / technologies / services and technology brokerage; support activities for licensing IPR / intangible assets and knowledge capital; assistance for negotiating Research Development Innovation and Tech Transfer contracts; assistance for invention disclosures, filing and granting patents and other IPR instruments and their valorization; assistance in developing spin-off / start-up companies and innovative business models and support activities for managing the 
portfolio of intangible assets that needs professional expertise (technical, economic, financial).

\begin{tabular}{|c|c|c|c|c|c|c|c|c|c|}
\hline KR- KA & A1 & A2 & A3 & A4 & A5 & A6 & A7 & A8 & A9 \\
\hline \multicolumn{10}{|l|}{ KR1 } \\
\hline \multicolumn{10}{|l|}{ KR2 } \\
\hline \multicolumn{10}{|l|}{ KR3 } \\
\hline \multicolumn{10}{|l|}{ KR4 } \\
\hline \multicolumn{10}{|l|}{ KR1 } \\
\hline \multicolumn{10}{|l|}{ KR2 } \\
\hline \multicolumn{10}{|l|}{ KR3 } \\
\hline \multicolumn{10}{|l|}{ KR4 } \\
\hline \multicolumn{10}{|l|}{ KR1 } \\
\hline \multicolumn{10}{|l|}{ KR2 } \\
\hline \multicolumn{10}{|l|}{ KR3 } \\
\hline \multicolumn{10}{|l|}{ KR4 } \\
\hline \multicolumn{10}{|l|}{ KR1 } \\
\hline \multicolumn{10}{|l|}{ KR2 } \\
\hline \multicolumn{10}{|l|}{ KR3 } \\
\hline KR4 & & & & & & & & & \\
\hline
\end{tabular}

PICBE | 1045

MODEL "COST CENTER"

MODEL "REVENUE CENTER"

MODEL "PROFIT CENTER"

MODEL "VALUE CENTER

KR - KEY RESOURCES

KR1 - technical facilities (own and/or in cooperation / partnership)

KR2 - multi media facilities in host institution and logistics for events

KR3 - professional expertise (technical, economic, financial)

KR4 - authorized programs for education / professional training

KA - KEY ACTIVITIES

A1 - Support activities for selling innovative

products / technologies / services and

technology brokerage

A2 - Support activities for licensing IPR /

intangible assets and knowledge capital

A3 - Assistance for negotiating Research

Development Innovation and Tech Transfer contracts

A4 - Assistance for developing experimental models and prototypes

A5 - Assistance for invention disclosures, filing

and granting patents and other IPR

instruments and their valorization

A6 - Assistance in developing spin-off / start-

up companies and innovative business models

A7 - Professional training and logistic support

in knowledge / technology transfer

A8 - Organizing thematic events and support

for dissemination, promotion, marketing in

technology commercialization

A9- Support activities for managing the

portfolio of intangible assets

Figure 7. Pairing "key" activities with "key" resources

Source: Authors' own research.

\section{Step 7 - pairing "key" resources with "key" partnerships}

Some "key" resources aren't available "in-house" and are ensured in partnership, grid of correspondence being presented in Figure 8. Certain technical facilities could be offered in cooperation with entities from ReNITT or outside this network, namely centers for technological development. Multi-media endowments could be shared with entities from ReNITT or with certain clusters / competitiveness poles, and specific professional competences could be "borrowed" also from such external entities. Authorized professional training are available in cooperation with specialized NGOs, these structures being widely spread in the educational market. 


\begin{tabular}{|c|c|c|c|c|c|}
\hline KR - KP & KP1 & KP2 & KP3 & KP4 & KP5 \\
\hline \multicolumn{6}{|l|}{ KR1 } \\
\hline \multicolumn{6}{|l|}{ KR2 } \\
\hline \multicolumn{6}{|l|}{ KR3 } \\
\hline \multicolumn{6}{|l|}{ KR4 } \\
\hline \multicolumn{6}{|l|}{ KR1 } \\
\hline \multicolumn{6}{|l|}{ KR2 } \\
\hline \multicolumn{6}{|l|}{ KR3 } \\
\hline \multicolumn{6}{|l|}{ KR4 } \\
\hline \multicolumn{6}{|l|}{ KR1 } \\
\hline \multicolumn{6}{|l|}{ KR2 } \\
\hline \multicolumn{6}{|l|}{ KR3 } \\
\hline \multicolumn{6}{|l|}{ KR4 } \\
\hline \multicolumn{6}{|l|}{ KR1 } \\
\hline \multicolumn{6}{|l|}{ KR2 } \\
\hline \multicolumn{6}{|l|}{ KR3 } \\
\hline \multicolumn{6}{|l|}{ KR4 } \\
\hline & & & & & \\
\hline \multicolumn{6}{|l|}{ MODEL "COST CENTER" } \\
\hline \multicolumn{6}{|l|}{ MODEL "REVENUE CENTER" } \\
\hline \multicolumn{6}{|l|}{ MODEL "PROFIT CENTER" } \\
\hline \multicolumn{6}{|l|}{ MODEL "VALUE CENTER" } \\
\hline \multicolumn{6}{|l|}{ KR - KEY RESOURCES } \\
\hline \multicolumn{6}{|c|}{ KR1 - technical facilities (own and/or in cooperation / partnership) } \\
\hline \multicolumn{6}{|c|}{ KR2 - multi media facilities in host institution and logistics for events } \\
\hline \multicolumn{6}{|c|}{ KR3 - professional expertise (technical, economic, financial) } \\
\hline \multicolumn{6}{|c|}{ KR4 - authorized programs for education / professional training } \\
\hline \multirow{2}{*}{\multicolumn{6}{|c|}{ KP - KEY PARTNERS }} \\
\hline & & & & & \\
\hline \multicolumn{6}{|l|}{$\begin{array}{l}\text { KP1 - entities from ReNITT } \\
\text { (technology transfer centers, } \\
\text { technology information } \\
\text { centers, business / } \\
\text { technology incubators, } \\
\text { scientific / technological } \\
\text { parks) }\end{array}$} \\
\hline \multicolumn{6}{|l|}{$\begin{array}{l}\text { KP2 - technology transfer } \\
\text { organizations (technology } \\
\text { transfer centers, business / } \\
\text { technology incubators, } \\
\text { scientific / technological } \\
\text { parks etc.) outside ReNITT }\end{array}$} \\
\hline \multicolumn{6}{|c|}{ KP3 - innovative clusters, competitiveness poles } \\
\hline KP4 - technological developn & ent ce & s, innovat & on / living & labs etc. & \\
\hline KP5 - regional development & gencie & GOs, publ & cauthoriti & & \\
\hline
\end{tabular}

Figure 8. Pairing "key" resources with "key" partnerships

Source: Authors' own research.

\section{Step 8 - pairing "key" activities with cost structure}

Cost structure associated to each TTOs activity is grouped in two main categories: fixed costs (salaries, consumables, utilities, overheads) and variable costs (events participation / organization, travel, endowments, professional training, certifications, marketing and advertising, patenting / royalties for inventors / developing experimental models etc.), their distribution being presented in Figure 9. Only 3 activities (A3 - Assistance for negotiating Research Development Innovation and Tech Transfer contracts; A6 - Assistance in developing spin-off / start-up companies and innovative business models and A9 - Support activities for managing the portfolio of intangible assets) suppose existence of only fixed costs, all other 6 (A1 - Support 
activities for selling innovative products / technologies / services and technology brokerage; A2 - Support activities for licensing IPR / intangible assets and knowledge capital; A4 - Assistance for developing experimental models and prototypes; A5 Assistance for invention disclosures, filing and granting patents and other IPR instruments and their valorization; A7 - Professional training and logistic support in knowledge / technology transfer and A8 - Organizing thematic events and support for dissemination, promotion, marketing in technology commercialization) requesting existence of both costs types (fixed and variable), divided in different percentages, according to the specific of each activity.

\begin{tabular}{|c|c|c|c|c|c|c|c|c|c|}
\hline $\mathrm{COS}-\mathrm{KA}$ & A1 & A2 & A3 & A4 & A5 & A6 & A7 & A8 & A9 \\
\hline $\operatorname{Cos} 1$ & $60 \%$ & $50 \%$ & $100 \%$ & $60 \%$ & $60 \%$ & $100 \%$ & $70 \%$ & $50 \%$ & $100 \%$ \\
\hline $\cos 2$ & $40 \%$ & $50 \%$ & & $40 \%$ & $40 \%$ & & $30 \%$ & $50 \%$ & \\
\hline $\cos 1$ & $70 \%$ & $60 \%$ & $100 \%$ & $70 \%$ & $70 \%$ & $100 \%$ & $80 \%$ & $50 \%$ & $100 \%$ \\
\hline $\cos 2$ & $30 \%$ & $40 \%$ & & $30 \%$ & $30 \%$ & & $20 \%$ & $50 \%$ & \\
\hline $\cos 1$ & $65 \%$ & $55 \%$ & $100 \%$ & $65 \%$ & $65 \%$ & $100 \%$ & $75 \%$ & $50 \%$ & $100 \%$ \\
\hline $\cos 2$ & $35 \%$ & $45 \%$ & & $35 \%$ & $35 \%$ & & $25 \%$ & $50 \%$ & \\
\hline $\cos 1$ & $80 \%$ & $70 \%$ & $100 \%$ & $80 \%$ & $80 \%$ & $100 \%$ & $80 \%$ & $60 \%$ & $100 \%$ \\
\hline $\cos 2$ & $20 \%$ & $30 \%$ & & $20 \%$ & $20 \%$ & & $20 \%$ & $40 \%$ & \\
\hline & & & & & & & & & \\
\hline \multicolumn{10}{|l|}{ MODEL "COST CENTER" } \\
\hline \multicolumn{10}{|l|}{ MODEL "REVENUE CENTER" } \\
\hline \multicolumn{10}{|l|}{ MODEL "PROFIT CENTER" } \\
\hline \multicolumn{10}{|l|}{ MODEL "VALUE CENTER" } \\
\hline \multicolumn{10}{|l|}{ COS - COST STRUCTURE } \\
\hline \multicolumn{10}{|c|}{ CoS1 - fixed costs (salaries, consumables, utilities, overheads) } \\
\hline \multicolumn{10}{|l|}{$\begin{array}{l}\text { CoS2 - variable costs (events participation / } \\
\text { organization, travel, endowments, professional } \\
\text { training, certifications, marketing and } \\
\text { advertising, patenting / royalties for inventors / } \\
\text { developing experimental models etc.) }\end{array}$} \\
\hline \multicolumn{10}{|l|}{ KA - KEY ACTIVITIES } \\
\hline \multicolumn{10}{|l|}{$\begin{array}{l}\text { A1 - Support activities for selling innovative } \\
\text { products / technologies / services and } \\
\text { technology brokerage }\end{array}$} \\
\hline \multicolumn{10}{|l|}{$\begin{array}{l}\text { A2 - Support activities for licensing IPR / } \\
\text { intangible assets and knowledge capital }\end{array}$} \\
\hline \multicolumn{10}{|l|}{$\begin{array}{l}\text { A3 - Assistance for negotiating Research } \\
\text { Development Innovation and Tech Transfer } \\
\text { contracts }\end{array}$} \\
\hline \multicolumn{10}{|l|}{$\begin{array}{l}\text { A4 - Assistance for developing experimental } \\
\text { models and prototypes }\end{array}$} \\
\hline \multicolumn{10}{|l|}{$\begin{array}{l}\text { A5 - Assistance for invention disclosures, filing } \\
\text { and granting patents and other IPR instruments } \\
\text { and their valorization }\end{array}$} \\
\hline $\begin{array}{l}\text { A6 - Assistance in developing spin-off / start-up } \\
\text { companies and innovative business models }\end{array}$ & & & & & & & & & \\
\hline \multirow{2}{*}{\multicolumn{10}{|c|}{$\begin{array}{l}\text { knowledge / technology transfer } \\
\text { A8- Organizing thematic events and support for } \\
\text { dissemination, promotion, marketing in } \\
\text { technology commercialization }\end{array}$}} \\
\hline & & & & & & & & & \\
\hline $\begin{array}{l}\text { A9-Support activities for managing the portfolio } \\
\text { of intangible assets }\end{array}$ & & & & & & & & & \\
\hline
\end{tabular}

\section{Figure 9. Pairing "key" activities with cost structure}

Source: Authors' own research.

Summarizing, the qualitative and quantitative analysis, done in the above presented frame of the 8 steps scheduling of pairing the building blocks of the four Business Models Canvas, corresponding to the specific technology transfer models, and taking into account the elements of the value chain of technology transfer and making connections with technology readiness level, this original and innovative approach allows a clarification of this relative "fuzzy" and complicated modeling process of university's TTOs activities, gathering in a concentrated format all necessary information. 


\section{Conclusions}

By using business models as instruments for analysis and acknowledgement of the technology transfer processes from universities to social and economic environment, is possible to work with several scenarios that, in the frame of using adequate flexible mechanisms of thinking and acting, are capable to support development strategies for PICBE | 1048 academic environment.

Services offered by a TTO to its clients are placed in different regions of the value chain, from which the most important is the exploration of knowledge based opportunities (specify their needs related to technologies, production equipment, patents, research; access ideas and information on relevant technologies, equipment, and patents; access to qualified research). Still, if anyone implicated in technology transfer process is not capable to understand the importance of services addressing access to capital and commercialization of technologies, respectively the relation between services offered at the validation stage and services linked to the legal issues of the exploitation stage, this fact could lead to the insufficient exploitation of synergies, and diminish TTOs' revenues and performance.

University knowledge and technology transfer organizations are less interested to provide customized solutions for single client firms, to serve a specific market segment of firms and to generate money revenues from the sales of services to firms, so they do not appear to have a distinctive / adequate business model, being hosted by larger organizations and having the mandate to advance, validate, and exploit research-based opportunities, i.e. an undifferentiated knowledge and technology transfer business model. In this respect, the managers of TTOs are more interested to offer services related to the large research knowledge-based opportunities they have access to and to find market opportunities to exploit them.

According to their mission, objectives and strategies, universities decide upon a certain business model for the TTOs, adaptable to client segment and value proposition to attain, by the offered services portfolio. In conclusion, during their activities, TTOs identify, validate and exploit the opportunities originated from applicative research results, by "technology push" methods. Also, there are necessary specific competences (human and material) to develop externally aware business models starting from real needs of the clients, by "market pull" techniques, that would contribute to enhance the endogenous innovation potential of firms.

\section{References}

Baglieri, D., Baldi, F., Tucci, C. (2015), “University Technology Transfer Office Business Models: One Size does NOT Fit All", DRUID2015 Conference on "The RELEVANCE of INNOVATION", June 15-17, 2015 at LUISS BS in Rome, Italy.

Landry, R., Amara, N., Cloutier, J.S., Halilem, N. (2013), “Technology transfer organizations: Services and business models", Technovation 33, available at: http://dx.doi.org/10.1016/j.technovation.2013.09.008, pp. 431-449.

Marin, A., Boanță, L., Hadăr, A., Badea, D.M., Vlăduț, G., Bucur, D., Ciocănel, B., Ivan, I. (2015), "Business Models and Competitive Advantage for Technology Transfer 
Entities", THE ROMANIAN REVIEW PRECISION MECHANICS, OPTICS \& MECHATRONICS; nr. 48/2015, ISSN 2247-7063, pp. 103-109.

PICBE | 1049 